\title{
Laboratory capability for molecular detection and confirmation of novel coronavirus in Europe, November 2012
}

D Palm¹, D Pereyaslov², J Vaz¹, E Broberg ${ }^{1}$, H Zeller ${ }^{1}$, D Gross², C S Brown², M J Struelens (marc.struelens@ecdc.europa.eu) ${ }^{1}$, on behalf of the Joint ECDC-WHO Regional Office for Europe Novel Coronavirus Laboratory Survey participants; ECDC National Microbiology Focal Points, WHO European Region EuroFlu Network and European Network for Diagnostics of "Imported" Viral Diseases (ENIVD) ${ }^{3}$

1. European Centre for Disease Prevention and Control (ECDC), Stockholm, Sweden

2. World Health Organization (WHO) Regional Office for Europe, Copenhagen, Denmark

3. Joint ECDC-WHO Regional Office for Europe Novel Coronavirus Laboratory Survey participants; ECDC National Microbiology Focal Points, WHO European Region EuroFlu Network and European Network for Diagnostics of “Imported" Viral Diseases (ENIVD)

Citation style for this article:

Palm D, Pereyaslov D, Vaz J, Broberg E, Zeller H, Gross D, Brown CS, Struelens MJ, on behalf of the Joint ECDC-WHO Regional Office for Europe Novel Coronavirus

Laboratory Survey participants; ECDC National Microbiology Focal Points, WHO European Region EuroFlu Network and European Network for Diagnostics of

“Imported" Viral Diseases (ENIVD). Laboratory capability for molecular detection and confirmation of novel coronavirus in Europe, November 2012 . Euro Surveill. "Imported" Viral Diseases (ENIVD). Laboratory capability for molecular detection and confirmation of novel cor

Article submitted on 05 December 2012 / published on 6 December 2012

A rapid survey by the European Centre for Disease Prevention and Control (ECDC) and the World Health Organization (WHO) Regional Office for Europe ascertained the availability of national reference laboratory testing for a recently detected novel coronavirus as of 28 November 2012. Screening by internal quality controlled upE-RT-PCR assay was available in 23/46 of responding countries in the WHO European Region, of which 19/30 in European Union (EU) and European Economic Area (EEA) countries. Confirmation of positive screened samples by either $O R F 1 b-R T-P C R$, or other target RT-PCR assays with sequence analysis or whole-genome sequence analysis was available in $22 / 46$ responding countries of which $18 / 30$ in EU/EEA countries.

In September 2012, a novel coronavirus was first characterised by genome sequencing at the Erasmus Medical Center (EMC) of a viral isolate from a patient in Saudi Arabia with severe pneumonia [1-2]. This virus belongs to the genus beta-coronavirus and is closely related to some bat coronaviruses. Since then, a total of nine confirmed cases of human infection with the novel coronavirus have been reported to public health authorities and WHO [3-6]. These patients developed a severe respiratory disease in Saudi Arabia, Qatar and Jordan over the period April to November 2012 and five had a fatal outcome [1-6]. Two patients were referred to Europe for specialised care [1-6].

Coronaviruses are membrane enveloped viruses with large RNA genomes and a distinctive surface crown causing respiratory and enteric infections in humans and animals. In 2003, zoonotic transmission of SARSCoV caused a worldwide epidemic associated with more than 8,000 cases of severe acute respiratory syndrome (SARS) and a case-fatality rate of $10 \%[7]$.

\section{Monitoring of novel coronavirus}

While the reservoir and mode of transmission of the novel coronavirus virus are under investigation, WHO and ECDC request that any probable or confirmed case that is diagnosed should rapidly (i) be reported to national authorities to enable them to take appropriate public health measures, and (ii) be notified to WHO under the International Health Regulations (2005) and simultaneously through joint reporting system to the Early Warning and Response System (EWRS) for countries in the EU/EEA $[3,4,8]$.

In September 2012, Corman et al described the first diagnostic assays for the novel coronavirus [9]. These involve a two-step screening and confirmation testing algorithm using newly developed specific RT-PCR assays that target the regions upstream of the $E$ gene (the $u p E$ target; recommended for screening) and open reading frame $1 \mathrm{~b}\left(O R F_{1} b\right.$; recommended for confirmation) [9]. Additional testing based on sequence analysis of other viral genome targets or whole genome sequence determination from clinical material or culture isolate can also be used to confirm cases $[2,6]$.

A number of pan-coronavirus RT-PCR assays have been described which target the polymerase gene of coronaviruses used for the detection of known and unknown coronaviruses, including coronaviruses currently circulating in humans such as hCoV-229E, hCoV-NL63, hCoV-OC 43 and SARS-CoV [10-12]. Some of these pancoronavirus RT-PCR assays may be also used to detect the novel coronavirus. However, a positive result should be confirmed by screening for the specific targets described for hCoV-EMC, sequencing of the RT-PCR product and/or virus isolation $[1,2,6]$. 
Availability of laboratory tests for detection and confirmation of novel coronavirus in European Union/ European Economic Area countries and the member states of the World Health Organization European region, per country, 28 November 2012

\begin{tabular}{|c|c|c|}
\hline \multirow{2}{*}{ Experiment } & \multicolumn{2}{|c|}{ Number of countries } \\
\hline & EU/EEA countries $(\mathrm{N}=30)$ & WHO European Region $(\mathrm{N}=46)$ \\
\hline \multicolumn{3}{|l|}{ Screening tests according to [8] } \\
\hline No screening or confirmation test & 7 & 17 \\
\hline upE RT-PCR (without positive control) & 4 & 6 \\
\hline upE RT-PCR (with positive control) & 19 & 23 \\
\hline \multicolumn{3}{|l|}{ Confirmation test according to [8]) } \\
\hline Confirmation of positive upE RT-PCR by ORF1b RT-PCR & 14 & 17 \\
\hline Confirmation of positive upE RT-PCR by sequencing of ORF1b & 13 & 15 \\
\hline \multicolumn{3}{|l|}{ Other confirmation tests } \\
\hline $\begin{array}{l}\text { Confirmation of positive RT-PCR by sequencing of pan- } \\
\text { coronavirus RT-PCR product }\end{array}$ & 10 & 11 \\
\hline $\begin{array}{l}\text { Confirmation of positive RT-PCR by whole viral genome } \\
\text { sequencing }\end{array}$ & 7 & 8 \\
\hline
\end{tabular}

EU/EEA: European Union/ European Economic Area; WHO World Health Organization

The rapid communication of technical protocols of validated diagnostic assays and distribution of positive RNA control material is essential to provide public health laboratories with the means to screen and confirm cases of this emerging viral disease and allow for appropriate public health response $[4,8,13]$. WHO is developing laboratory testing guidance on the detection of the novel coronavirus. To obtain background information for the updated guidance and to identify the needs for support by ECDC and WHO Regional Office for Europe to virology laboratories for case ascertainment across Europe, the capability of national laboratories was jointly investigated by questionnaire surveys.

\section{Survey on novel coronavirus detection capabilities}

Two coordinated surveys were administered by email from ECDC and the WHO Regional Office. The ECDC survey was sent to the National Microbiology Focal Points of the 30 EU/EEA countries and in the EU accession country Croatia and to contact points for laboratories in the European Network for Diagnostics of "Imported" Viral Diseases (ENIVD) [14], on 26 November 2012. The Regional Office survey was sent to EuroFlu National Focal Points in 53 countries in the WHO European Region on 26 November 2012, with a deadline set for 29 November. Some EU/EEA institutions belonging to more than one network received and returned both questionnaires. Reminders were sent to the networks after 29 November and an additional 10 replies, received by 3 December, were included in this report.
The ECDC survey questions covered five areas: national laboratories involved in testing for novel coronavirus, availability of laboratory tests and positive controls, laboratory tests under development, sampling strategy and test referral, and need for support. The Regional Office survey questions covered the following areas: confirmation if the WHO-recognised National Influenza Centre (NIC) or other laboratory serve as national reference laboratory for novel coronavirus testing, availability of laboratory tests and positive controls, and need for support.

Data were validated with request for clarification by the survey respondents on 3 December and confirmed data were received by 4 December 2012 . Hereafter data from both surveys were merged, duplicate responses removed and validated data analysed jointly by ECDC and Regional Office.

\section{Survey results}

The response rates were $93 \%$ (28/30 countries) for the EU/EEA countries included in the ECDC survey and $76 \%$ (40/53 countries) for the WHO Regional Office survey; taken together, the surveys captured data from 46/53 of WHO European Region Member States and all EU/ EEA countries. In total, information was provided by 47 countries responding to one or both questionnaires.

The table indicates which molecular tests were available for novel coronavirus detection and confirmation at national reference or expert laboratory level at the time of the survey. According to recommendations $[9,14]$ screening by internal quality controlled upE- RT-PCR assay was available in $23 / 46$ of responding WHO European Region countries and 19/30 EU/EEA 
Countries in the World Health Organization (WHO) European Region with capacity for screening and confirmation of novel coronovairus infection, 28 November 2012

\section{No response}

No upE RT-PCR screening

Only upE RT-PCR screening without RNA control

Only upE RT-PCR screening with RNA control

PT-PCR screening and confirmation assays

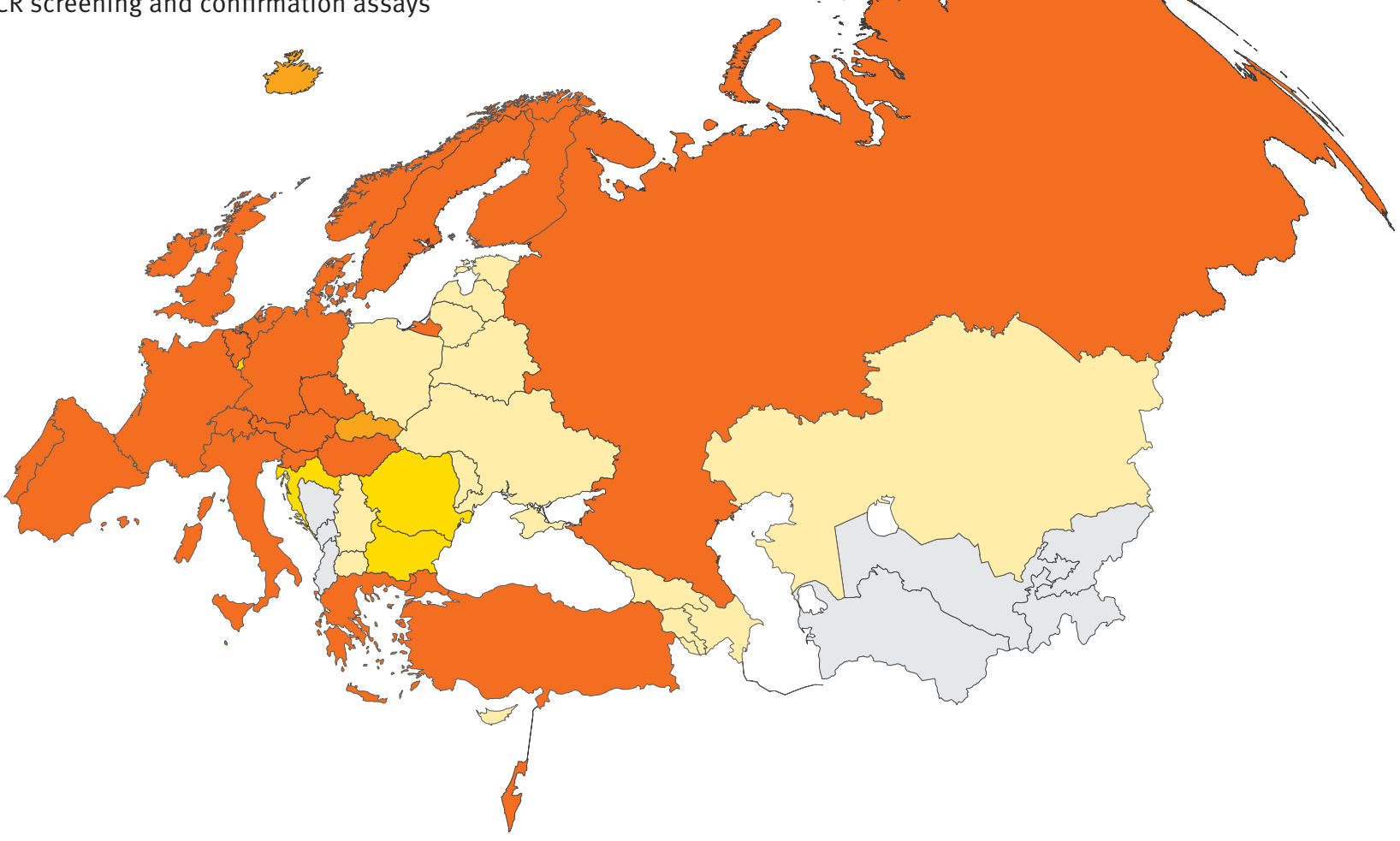

countries. Confirmation of positive screened samples by either ORF1b - RT-PCR, other target RT-PCR assays with sequence analysis or whole genome sequence analysis was available in 18/30 EU/EEA countries and in 22/46 responding WHO European Region countries.

The figure indicates the level of screening and confirmation assays available in the 47 responding countries, including 46 WHO European Region Member States, 27 EU Member States and three EEA countries, two of which are also Member States of WHO European Region.

Many countries indicated that their reference laboratories were developing specific molecular detection tests, serological assays or were awaiting positive RNA control material for RT-PCR assays. Therefore, it should be emphasised that the results presented here are an overview of laboratory tests in operation at the time of survey and will require updating as capacities are rapidly increasing in the participating countries.

In 25 countries, the NIC reported to be the national reference laboratory for novel coronavirus and in 17 of these countries it was the only laboratory reporting diagnostic capability. In 10 countries, more than one laboratories were reported to perform novel coronavirus diagnostic tests at national or regional levels. Twenty laboratories that reported diagnostic capability from 12 countries were members of ENIVD.

Twelve of 25 countries with no confirmation capacity at national level reported referral arrangements to ship samples for testing in another country.

Of note, laboratories in six EU/EEA countries indicated that samples had been tested to date for novel coronavirus from approximately 250 patients fulfilling the WHO definition patients under investigation. Of the nine cases reported so far to WHO from Saudi Arabia, Qatar and Jordan, in addition to in-country testing, three have been tested and confirmed by the Erasmus Medical Centre, Rotterdam, the Netherlands, the Health Protection Agency, London, United Kingdom, and the Robert Koch Institute, Berlin, Germany $[2,5,6]$.

\section{Conclusions}

The findings of this study indicate an extensive deployment of newly developed novel coronavirus molecular detection assays among public health reference and expert virology laboratories in Europe within only two 
months after sequence information on the first reported case was made available. This deployment occurred to a greater extent in EU/EEA countries of the WHO European Region compared with south-east and eastern European countries. Screening tests were available in nearly half of countries of the WHO European Region and cross-border shipment arrangements were in place in many of those lacking domestic testing capacity.

Our results will allow virologists and public health agencies, including ECDC and the WHO Regional Office, to remedy gaps within their laboratory networks. Such measures may include technical laboratory guidance and collaborative arrangements for cross-border referral testing of clinical materials, technical support such as distribution of reference control materials, assistance with development of quality controlled serological assays and, if warranted in the longer term, provision of capacity building courses and external quality assessment schemes.

\section{Acknowledgments}

We thank Christian Drosten, Ron Fouchier and Maria Zambon for kindly reviewing the survey questionnaire. We are also thankful to the ECDC National Microbiology Focal Points and members of the EURO-FLU and ENIVD networks for dedicated and rapid responses to the surveys.
References

1. ProMED-mail Novel coronavirus - Saudi Arabia: human isolate. Archive Number: 20120920.1302733. 20 September 2012. Available from: http://www.promedmail.org/direct. php?id=20120920.1302733

2. Van Boheemen S, de Graaf M, Lauber C, Bestebroer TM, Raj VS, Zaki AM, et al .2012. Genomic characterization of a newly discovered coronavirus associated with acute respiratory distress syndrome in humans. mBio. 2012;3(6). pii= e00473-12.

3. World Health Organization (WHO). Global Alert and Response: Background and summary of novel coronavirus infection - as of 30 November 2012. Geneva: WHO; 2012. Available from: http://www.who.int/csr/disease/coronavirus_infections/ update_20121130/en/index.html

4. European Centre for Disease Prvention and Control (ECDC). Rapid Risk assessment, update: Severe respiratory disease associated with a novel coronavirus, 26 November 2012. Stockholm: ECDC; 2012. Available from: http://ecdc.europa. eu/en/publications/Publications/Forms/ECDC_DispForm. aspx?ID=1007

5. Robert Koch Institute (RKI). Case of novel Corona virus in Germany 23 November 2012. Berlin: RKI; 2012. [Accessed 25 Nov 2012]. Available from: http://www.rki.de/EN/Home/ Corona_Virus.html;jsessionid $=77$ C1CoAF8994434233952DC28 C20E642.2_cid290

6. Bermingham A, Chand MA, Brown CS, Aarons E, Tong C, Langrish C, et al. Severe respiratory illness caused by a novel coronavirus, in a patient transferred to the United Kingdom from the Middle East, September 2012. Euro Surveill. 2012;17(40):pii=20290. Available from: http://www. eurosurveillance.org/ViewArticle.aspx?Articleld=20290

7. World Health Organization (WHO).Summary table of SARS cases by country, 1 November 2002 - 7 August 2003. Geneva: WHO; 2003. Available from: http://www.who.int/csr/sars/ country/2003_08_15/en/

8. World Health Organization (WHO). Case definition for case finding severe respiratory disease associated with novel coronavirus. Geneva: WHO; 2012. Available from: http://www. who.int/csr/disease/coronavirus infections/case definition/ en/index.html

9. Corman VM, Eckerle I, Bleicker T, Zaki A, Landt O, EschbachBludau $M$, et al. Detection of a novel human coronavirus by real-time reverse-transcription polymerase chain reaction. Euro Surveill. 2012;17(39):pii=20285. Available from: http:// www.eurosurveillance.org/ViewArticle.aspx?Articleld $=20285$

10. Vijgen L, Moes E, Keyaerts E, Li S, Van Ranst M. A pancoronavirus RT-PCR assay for detection of all known coronaviruses. Methods Mol Biol. 2008;454: 3-12.

11. Drosten C, Günther S, Preiser W, van der Werf S, Brodt HR, Becker $\mathrm{S}$ et al. Identification of a novel coronavirus in patients with severe acute respiratory syndrome. N Engl J Med. 2003;348(20):1967-76.

12. Bermingham A, Heinen P, Iturriza-Gómara M, Gray J, Appleton $\mathrm{H}$, Zambon MC. Laboratory diagnosis of SARS. Philos Trans R Soc Lond B Biol Sci. 2004;359(1447):1083-9.

13. Pebody RG, Chand MA, Thomas HL, Green HK, Boddington NL, Carvalho C, et al. The United Kingdom public health response to an imported laboratory confirmed case of a novel coronavirus in September 2012. Euro Surveill. 2012;17(40): pii=20292. Available from: http://www. eurosurveillance.org/ViewArticle.aspx?Articleld=20292

14. European Network for Diagnostics of "Imported" Viral Diseases (ENIVD). Available from: www.enivd.org 